\title{
Antimicrobial Resistance and Plasmid Profiles of Salmonella enterica Serovars from Different Sources in Lagos, Nigeria
}

\author{
K. O. Akinyemi ${ }^{*}$, S. O. Ajoseh" ${ }^{1}$, B. A. Iwalokun ${ }^{2}$, A. O. B. Oyefolu ${ }^{1}$, C. O. Fakorede ${ }^{1}$, \\ R. O. Abegunrin ${ }^{1}$, O. Adunmo ${ }^{1}$ \\ ${ }^{1}$ Department of Microbiology, Lagos State University, Ojo, Lagos, Nigeria \\ ${ }^{2}$ Biochemistry Unit and Malaria Research Laboratory, Nigerian Institute of Medical Research, Yaba, Lagos, Nigeria \\ Email: *akinyemiko@yahoo.com, *kabiru.akinyemi@lasu.edu.ng
}

How to cite this paper: Akinyemi, K.O., Ajoseh, S.O., Iwalokun, B.A., Oyefolu, A.O.B., Fakorede, C.O., Abegunrin, R.O. and Adunmo, O. (2018) Antimicrobial Resistance and Plasmid Profiles of Salmonella enterica Serovars from Different Sources in Lagos, Nigeria. Health, 10, 758-772.

https://doi.org/10.4236/health.2018.106058

Received: May 4, 2018

Accepted: June 19, 2018

Published: June 22, 2018

Copyright $\odot 2018$ by authors and Scientific Research Publishing Inc. This work is licensed under the Creative Commons Attribution International License (CC BY 4.0).

http://creativecommons.org/licenses/by/4.0/

\section{(c) (i) Open Access}

\begin{abstract}
Introduction: Salmonella enterica Serovars remains one of the leading pathogens that cause diarrhoea and bloodstream infections in developing countries. The emergence of multidrug resistant (MDR) Salmonella has become a serious problem globally. This study investigated the antibiotic resistance and plasmid profiles of Salmonella isolates from different sources. Methods: Seventy-three samples comprised of clinical (30), hand swab (15), food (10) and water (18) were analyzed bacteriologically. Salmonella isolates were identified and characterized by standard procedures. Isolates were subjected to antimicrobial susceptibility testing and were further screened for plasmid DNA by standard methods. Results: A total of 27 Salmonella isolates made up of 5 (18.5\%) S. typhi, 6 (22.2\%) S. enteritidis, 9 (33.3) S. typhimurium, 5 (18.5\%) S. cholerasuis, and 1 (3.7\%) each of $S$. arizonae and $S$. vichow were obtained in this study. All the isolates developed resistance to three or more antibiotics evaluated. Four distinct resistance profiles: TetAmpCol, TetAmpColCot, TetAmpColCip and TetAmpColCotCip were recorded with $63 \%$ of the isolates exhibiting resistance profile TetAmpColCot. Specifically 23 of 27 (85.2\%) of the isolates harboured plasmid DNA comprised of 12 distinct plasmid profiles of different sizes ranging from $3.2 \mathrm{~kb}$ to $30.2 \mathrm{~kb}$. Salmonella isolates of the same species from different sources differed in plasmid profile. Plasmid profile was found to show good discriminatory capability compared to antibiotics resistance profile. Conclusion: This study revealed that both resistance antibiogram and plasmid profile are still viable epidemiological tools for tracing the source of Salmonella isolates. A need for prudent use of antibiotics is suggested.
\end{abstract}




\section{Keywords}

Salmonella, Resistant, Antibiogram, Plasmid, Epidemiology, Disease

\section{Introduction}

The genus Salmonella belongs to the family Enterobacteriaceae. They are facultative anaerobic rods. Salmonella is mostly motile except Salmonella pollurun and Salmonella galarum, non-spore forming, Gram-negative bacterium [1]. There are currently over 2587 serotypes of Salmonella, responsible for salmonellosis, grouped into two basic species: Salmonella enterica and Salmonella bongori [2] [3] [4]. Salmonella spp. is mainly transmitted by the fecal-oral route mainly through contaminated food or water [4]. Outbreaks of Salmonella-associated diseases are usually associated with contaminated water and the ingestion of contaminated food of animal origin like, fishes, poultry, meat and milk [5] [6] [7].

Salmonella enterica is an important cause of human morbidity and mortality worldwide [8] [9] [7]. Salmonella enterica Serovar Typhi is the etiological agent of typhoid fever while non-typhoid Salmonella species (NTS) are associated with gastroenteritis and invasive infection in children, the elderly and immune compromised patients; these include: Salmonella typhimurium, Salmonella enteritidis amongst other serovars of Salmonella enterica that affect both human and animal, of which S. typhi affects human only [10] [11]. Both Salmonella typhi and NTS are among the most frequent pathogens causing blood stream infections (BSI) in tropical low-resource settings [11]. The highest incidence and prevalence of Salmonella infection worldwide occur in Asia region [8] [12] [13], mainly in south and southeast Asia, where isolates show high rate of antibiotic resistance [13] [14] [15]. It is estimated that each year there are approximately 21.6 million cases of typhoid fever which result in 200,000 deaths worldwide [16]. However, the incidence of cases and death has been greatly increased by combination of poor sanitation and hygiene, unavailability of vaccines and high cost of effective antimicrobial chemotherapy [16].

In Nigeria, the antibiotics mostly readily available for treatment of typhoid and other Salmonella related diseases are Chloramphenicol, Ampicillin, and Tetracycline, third generation Cephalosporin, Gentamycin, Quinolones and Trimethoprim/Sulfamethoxazole [17] [18]. Recently multi-drug resistant (MDR) strains have emerged presumably due to the extensive use of antimicrobial both in human and animals husbandry [19] [20] [21]. In veterinary medicine for instance, antibiotics are being used in livestock production, disease prevention and as growth-promoting feed additives [5] [22]. The use of antibiotics in animals' production disrupts the normal floral of the intestine; prolongs faecal shedding of these organisms into the environment and emergence of antibiotics-resistant Salmonella strains [14] [23]. MDR in Salmonella is a cause of great concern in 
both clinical and veterinary medicine, as it may limit the therapeutic options available for the treatment of Salmonella-associated diseases [24] [25] [26]. Resistance had been carried out on plasmids or the chromosomes of resistant bacteria [27]. Plasmids have been a major factor in the spreading antibiotic resistance between bacteria [28] [29]. Under antibiotic selective pressure, resistant-plasmids (R-plasmids) spread resistance makers between both homologous and heterologous bacterial communities [16]. Resistance to chloramphenicol, ampicillin and trimethoprim are generally plasmid encoded, although chromosomal resistance to ciprofloxacin which is associated with mutation at gryA, gryB and parC has been reported [20]. An epidemic MDR strain S. typhimurium phage type104 (DT104) has been identified as a major cause of salmonellosis in humans and animals in Europe and the United States [24] [27].

The increasing usage of antibiotics against Salmonella infections and other infectious diseases, which has continually affected the clinical outcomes, necessitated a need to carry out antimicrobial resistance surveillance study and plasmid profiles on Salmonella species from different sources in some communities in Lagos, Nigeria.

\section{Methods}

\subsection{Scope of Study and Sample Definition}

This study was conducted between June and September, 2014 in the department of microbiology, Lagos State University, Ojo and Nigeria Institute of Medical Research, Yaba, Lagos. A total of 73 samples comprising of 45 clinical samples (20 fecal, 15 hand swab and 10 blood) and 28 environmental samples (10 sachet water, 10 food and 8 well water) were aseptically collected within Badagry and Ojo Local Government Areas of Lagos State following standard procedures.

\subsection{Bacteriological Examination of Samples from Different Sources}

\subsubsection{Stool Samples}

A sterile wire loop was used to pick each stool sample collected and inoculated into selenite cysteine broth, then from the broth into petri dishes containing MacConkey agar (Oxoid, UK) using streak plate method. The inoculated plates were incubated at $37^{\circ} \mathrm{C}$ for $18-24$ hours. All isolates were characterized using standard techniques [30].

\subsubsection{Blood Samples}

Standard $0.5 \%$ bile salt broth containing $5 \mathrm{~g}$ of sodium taurocholate in 1 litre of sterile nutrient broth ( $\mathrm{pH} 7.6)$ and autoclaved at $108^{\circ} \mathrm{C}$ for 15 minutes, was used as enrichment broth. Approximately $3.0 \mathrm{ml}$ of each blood sample was inoculated into $27 \mathrm{ml}$. of the broth and incubation was at $37^{\circ} \mathrm{C}$ for 18 to 24 hours. Sub-cultured daily for 1 week onto Salmonella-Shigella agar (S-S agar M108, Himedia, Mumbai) was performed using freshly prepared medium every 3 days. Colonies were observed and isolates were characterized using standard 
techniques [30].

\subsubsection{Food Samples}

One gram analytical unit of each sample (white rice, jollof rice and meat) aseptically obtained from vendors was weighed out and was transferred into a sterile blender jar containing $9 \mathrm{ml}$ of peptone water and blended to give a suitable food homogenate. Serial dilutions of each sample were carried out. The pour plate technique was used for plating out the appropriate dilutions of sample $\left(10^{-2}\right.$ and $10^{-3}$ ). Molten MacConkey agar cooled to $45^{\circ} \mathrm{C}$ was dispensed over with the sample in each plate. Immediately, the sample and the molten agar were thoroughly and uniformly mixed by a gentle alternate rotation of the plates on the work benches. The solidified agar plate were inverted and incubated at $37^{\circ} \mathrm{C}$ for 24 48 hours. After incubation, colonies developing on plates with morphological characteristic of Salmonella were randomly picked and further inoculated on Salmonella-Shigella Agar (S-S agar M108, Himedia, Mumbai) to obtain a pure culture of Salmonella isolates. All isolates were characterized using standard techniques [30].

\subsubsection{Environmental Water Samples}

The multiple tube fermentation technique as described by Mackie and McCartney [31]. Briefly, varying quantities of each of the water samples were added to bottle containing broth (Oxoid, UK) of different strengths, with an inverted Durham tube in each bottle. The bottles were incubated under aerobic condition at $37^{\circ} \mathrm{C}$ for $18-24$ hours. For each test batch sterile water was used as control. After overnight incubation, subcultures from the positive broth were made onto Salmonella-Shigella Agar (SSA) (Oxoid, UK) and MacConkey Agar (Oxoid, UK) followed by subculturing on non-lactose fermenting colonies on triple sugar iron agar (TSIA) (Oxoid, UK). The inoculated media were incubated aerobically at $37^{\circ} \mathrm{C}$ for $18-24$ hours. All the isolates obtained were identified by standard methods (30). Further identification was by using API 20E (Espania) was used. Somatic and flagella antigens of isolated Salmonella species were performed using polyvalent antisera (Wellcome Diagnostic, UK).

\subsubsection{Hand Swab}

The left and right hand palms of the subjects (mainly among final year students of department of microbiology, Lagos State University) with the help of sterile cotton buds, soaked in $0.85 \%$ saline solution from define (fixed) area on the palm before and after hand washing. Hands were washed thoroughly with water and soap in their usual (regular) manner. These swabs were added into saline solutions of various dilutions under aseptic conditions and $0.2 \mathrm{~mL}$ of from each dilution was inoculated on sterilized MacConkey agar (Oxoid, UK) plate which was uniformly spread and incubated at $37^{\circ} \mathrm{C}$ for $24 \mathrm{~h}$. After Incubation, numbers of CFU were counted and different types of colonies were identified. Colonies were further subcutured on Salmonella-Shigella agar (S-S agar M108, Himedia, Mumbai) for the presence of non-lactose fermenting Salmonella spp. All isolates 
were characterized using standard techniques [32]

\subsection{Antibiogram of Salmonella Isolates}

Sensitivity of the pure culture of Salmonella isolates to different antibiotics was determined using the Kirby-Bauer disc diffusion technique and interpreted based on the guidelines of the Clinical and Laboratory Standards [33]. Discs used contained the following antibacterial agents: Ampicilin (AMP) $(10 \mu \mathrm{g}), \mathrm{Co}-$ trimoxazole (Cot) $(30 \mu \mathrm{g})$, Colistin (COL) $(10 \mu \mathrm{g})$, Ciprofloxacin(CIP) $(5 \mu \mathrm{g})$, Tetracyclin (TET) $(30 \mu \mathrm{g})$ Ceftriaxone (CRO) $(30 \mu \mathrm{g})$, Cefotaxime (CTX) (30 $\mu \mathrm{g})$, Cephalothin (CEF) $(30 \mu \mathrm{g})$, Imipenem (IMP) $(10 \mu \mathrm{g})$, Tetracyclin (TET) $(30$ $\mu \mathrm{g})$, Nitrofloxacin (NIT) $(10 \mu \mathrm{g})$ and Gentamicin (GEN) $(10 \mu \mathrm{g})$. Muella-Hinton $(\mathrm{MH})$ agar plates were swabbed with cells from the bacteria stock solution, already adjusted to the 0.5 Mac-Farland's turbidity standard. The discs were thereafter, carefully layered on the agar and incubated at $37^{\circ} \mathrm{C}$ for $24 \mathrm{H}$.

\subsection{Plasmid DNA Isolation from Salmonella Isolates}

Plasmid extraction was performed on all the isolates. It was done by using TENS-Mini Prep as described by [34]. Overnight culture $(1.5 \mathrm{ml})$ was $\mathrm{mi}-$ cro-centrifuged for one minute to pellet the cells. The supernatant was gently decanted, leaving $50-100 \mu$ together with cell pellet and vortex at high speed to re-suspend cells completely. TENS ( $300 \mu \mathrm{l})$ was then added, mixed by inverting tubes 3 - 5 times until the mixture becomes sticky. Potassium acetate (3.0 M, 150 $\mu \mathrm{l}, \mathrm{pH}$ 5.2) was then added and vortexed to mix completely. The mixture was micro-centrifuged at 10,000 rpm for $10 \mathrm{~min}$ to pellet cell debris and chromosomal DNA. The supernatant was then transferred into fresh tube and mixed well with $900 \mu \mathrm{l}$ of ice-cold absolute ethanol. The mixture was micro-centrifuged for 10 minutes to pellet plasmid DNA, (white pellet was observed). The supernatant was discarded, pellet rinsed twice with $1 \mathrm{ml}$ of $70 \%$ ethanol and dried. The pellet was re-suspended in $20-40 \mu \mathrm{l}$ of $10 \mathrm{mM}$ Tris $0.1 \mathrm{mM}$ EDTA buffer ( $\mathrm{pH}$ 7.6), and stored at $-4^{\circ} \mathrm{C}$ until further analysis.

\subsection{Gel Electrophoresis Preparation}

Immediately before loading the gel mix, $8 \mu \mathrm{l}$ of the plasmid DNA sample was prepared with $2 \mu \mathrm{l}$ of loading buffer (0.05 M EDTA, 20\% Ficoll, 0.25\% bromophenol blue, in $\mathrm{H}_{2} \mathrm{O}$ ). A horizontal electrophoresis apparatus was used, mini-gels was prepared as follows: about $25 \mathrm{ml}$ of $0.8 \%-1.0 \%$ low electroendosmosis (EEO) agarose in TBE buffer $(0.089 \mathrm{M}$ Tris, $0.089 \mathrm{M}$ boric acid, $0.0025 \mathrm{M}$ EDTA) was poured on a $10 \times 7 \mathrm{~cm}$ glass slide. Depending on the comb used, up to 14 samples can be run. The same TBE buffer is used as electrophoresis buffer. Usually the electrophoretic separation was done at 60 voltages for 6 hours. For visualization of DNA bands and photography, the intercalating dye ethydium bromide was used (proper care was taken as it is a carcinogenic compound). One drop of a $10 \mathrm{mg} / \mathrm{ml}$ stock solution was added to the staining tray containing 
water and the gel. The tray was covered with a lid. After staining for $30 \mathrm{~min}$ DNA bands were made visible under short UV light. A fundamental description of the application of agarose gel electrophoresis is as described [35].

\section{Results}

Twenty-seven Salmonella isolates made up of six Salmonella enterica Serovars: $S$. typhi, S. typhimurium, S. choleraesuis, S. enteritidis, S. virchow and S. arizonae were recorded from 73 samples from different sources in this study (Table 1). Of these, 11 isolates were from 20 feacal samples, 7 from 10 food samples, 3 from 8 well waters and 2 isolates each from 10, 10 and 15 sachet water, blood and hand swab respectively. The different serovars isolated from different sources was as shown in Table 1.

Eleven different antibiotics were tested against 27 Salmonella isolates identified. All the isolates (100\%) were resistant to at least three different antibiotics TET, AMP and COT. Also about $70 \%(\mathrm{n}=19)$ of the Salmonella isolates were resistant to four antibiotics TET, AMP, COL and COT. It is interesting to note that $S$. Typhi 02 and 04 had the highest resistance rate, with resistance to five different antibiotics TET, AMP, COL, COT and CIP. However, about $14 \%$ of the isolates developed resistance to CIP (Table 2).

Four distinct resistance profiles; A (TetAmpCol), B (TetAmpColCot), C (TetAmpColCip) and D (TetAmpColCotCip) were observed from the $27 \mathrm{Sal}$ monella isolates evaluated. Resistance profile B was most prevalent with $17 \mathrm{Sal}$ monella isolates exhibiting the trait, followed by profile A (six isolates). Two isolates each, exhibited resistance profiles $\mathbf{C}$ and $\mathrm{D}$. It was also observed that some Salmonella species exhibited more than one resistance profile, for instance S. enteritidis isolated from different sources had 3 resistance profiles A, B and C (Table 3).

Twenty-three out of the 27 Salmonella isolates harboured plasmid DNA ranging in size from $3.2 \mathrm{~kb}-30.2 \mathrm{~kb}$. We observed I2 distinct plasmid profiles among the isolates from different sources (Table 4 and Figures 1-3).

Table 1. Salmonella serovarss from different samples analyzed.

\begin{tabular}{|c|c|c|c|c|c|c|c|c|}
\hline \multirow{2}{*}{ Sources } & \multirow{2}{*}{$\begin{array}{l}\text { Number of } \\
\text { samples } \\
\text { collected }\end{array}$} & \multirow{2}{*}{$\begin{array}{l}\text { Number of } \\
\text { positive } \\
\text { samples }\end{array}$} & \multicolumn{6}{|c|}{ Salmonella isolates } \\
\hline & & & S. typhi & S. enteritidis & S. typhimurium & S. choleraesuis & S. virchow & S. arizonae \\
\hline Food & 10 & 7 & 2 & 2 & 3 & 0 & 0 & 0 \\
\hline Faeces & 20 & 11 & 3 & 2 & 1 & 3 & 1 & 1 \\
\hline Water-sachet & 10 & 2 & 0 & 1 & 1 & 0 & 0 & 0 \\
\hline Well-water & 8 & 3 & 0 & 1 & 2 & 0 & 0 & 0 \\
\hline Blood & 10 & 2 & 0 & 0 & 0 & 2 & 0 & 0 \\
\hline Hand swab & 15 & 2 & 0 & 0 & 2 & 0 & 0 & 0 \\
\hline Total & 73 & 27 & 5 & 6 & 9 & 5 & 1 & 1 \\
\hline
\end{tabular}


Table 2. Summary of antibiotics resistance of salmonella isolates.

\begin{tabular}{ccccccc}
\hline Salmonella ser.(n=27) & TET $(30 \mu \mathrm{g})$ & AMP $(10 \mu \mathrm{g})$ & COT $(30 \mu \mathrm{g})$ & COL $(10 \mu \mathrm{g})$ & CIP $(5 \mu \mathrm{g})$ & CRO, CEF, CTX, IMP, \\
\hline S. typhi $(5)$ & $5(18.5 \%)$ & $5(18.5 \%)$ & $4(14.8)$ & $5(18.5)$ & $3(11.1)$ & None \\
S. enteritidis $(6)$ & $6(22.2 \%)$ & $6(22.2 \%)$ & $4(14.8)$ & $6(22.2 \%)$ & $1(3.7)$ & None \\
S. typhimurium (9) & $9(33.3)$ & $9(33.3)$ & $7(25.9)$ & $9(33.3)$ & None & None \\
S. choleraesius (5) & $5(18.5 \%)$ & $5(18.5 \%)$ & $3(11.1)$ & $5(18.5 \%)$ & None & None \\
S. arizonae (1) & $1(3.7)$ & $1(3.7)$ & $1(3.7)$ & $1(3.7)$ & None & None \\
S. vichow (1) & $1(3.7)$ & $1(3.7)$ & None & $1(3.7)$ & None & None \\
\hline
\end{tabular}

Key: Ampicilin (AMP) $(10 \mu \mathrm{g})$, Cotrimoxazole (Cot) $(30 \mu \mathrm{g})$, Colistin (COL) $(10 \mu \mathrm{g})$, Ciprofloxacin (CIP) $(5 \mu \mathrm{g})$ and Tetracyclin (TET) (30 $\mu \mathrm{g})$, Ceftriaxone (CRO) $(30 \mu \mathrm{g})$, Cefotaxime (CTX) $(30 \mu \mathrm{g})$, Cephalothin (CEF) $(30 \mu \mathrm{g})$, Imipenem (IMP) (10 $\mu \mathrm{g})$, Tetracyclin (TET) $(30 \mu \mathrm{g})$, Nitrofloxacin(NIT) (10 $\mu \mathrm{g})$ and Gentamicin (GEN) $(10 \mu \mathrm{g})$.

Table 3. Resistance profile of Salmonella isolates obtained from the study.

\begin{tabular}{|c|c|c|c|c|c|c|c|c|}
\hline \multirow{2}{*}{ type } & \multirow{2}{*}{ Resistance pattern } & \multicolumn{6}{|c|}{ Salmonella isolates } & \multirow{2}{*}{ TOTAL } \\
\hline & & S. T & S.TP & S.E & S.CH & $S . \mathrm{V}$ & S. A. & \\
\hline $\mathrm{A}$ & TetAmpCol & 0 & 2 & 1 & 2 & 1 & 0 & 6 \\
\hline B & TetAmpColCot & 2 & 7 & 4 & 3 & 0 & 1 & 17 \\
\hline $\mathrm{C}$ & TetAmpColCip & 1 & 0 & 1 & 0 & 0 & 0 & 2 \\
\hline \multirow[t]{2}{*}{$\mathrm{D}$} & TetAmpColCotCip & 2 & 0 & 0 & 0 & 0 & 0 & 2 \\
\hline & TOTAL & 5 & 9 & 6 & 5 & 1 & 1 & 27 \\
\hline
\end{tabular}

KEYS: Ampicilin (AMP) $(10 \mu \mathrm{g})$, Cotrimoxazole (Cot) $(30 \mu \mathrm{g})$, Colistin (COL) $(10 \mu \mathrm{g})$, Ciprofloxacin (CIP) $(5 \mu \mathrm{g})$ and Tetracyclin (TET) $(30 \mu \mathrm{g}) . S$. T $(S$. typhi), S. TP (S. typhimurium), S. CH (S. choleraesuis), S.V (S. virchow), S. E (S. enteritidis), S. A (S. arizonae).

It was observed from this study that, 17 different Salmonella isolates showed the same resistance profile, TetAmpCol, which were of 9 different plasmid profiles ranging from $3.2 \mathrm{~kb}$ to $30.2 \mathrm{~kb}$ size. For instance, S. typhimurium 04 and 05 which were isolated from food with the same resistance profile TetAmpColCot, but harboured different plasmid sizes of $5.0 \mathrm{~kb}$ and $30.2 \mathrm{~kb}$ respectively. Also $S$. Typhi 02 and 04 isolated from faecal sample with the same resistance profile, TetAmpCol, possessed different plasmid profiles in which S. typhi 02 possess 2 different plasmid sizes of $17.5 \mathrm{~kb}$ and $30.2 \mathrm{~kb}$; and $S$. typhi 04 had 3 different plasmid sizes of $21.5 \mathrm{~kb}, 25 \mathrm{~kb}$ and $30.2 \mathrm{~kb}$.

It was also observed that some Salmonella isolates of the same species from diverse sources possessed different plasmid profiles. For instance, $S$. choleraesuis 01 (blood) and $S$. choleraesuis 04 (faeces) possessed the same resistance profile, TetAmpCol that differed in plasmid profiles in the sense that $S$. choleraesuis 01 (blood) had 2 plasmids ( $3.2 \mathrm{~kb}$ and $7.2 \mathrm{~kb}$ ) while $S$. choleraesuis 04 (faeces) possessed only one plasmid of $30.2 \mathrm{~kb}$ (Table 4).

\section{Discussion}

Salmonellosis caused by strains of Salmonella (both typhoidal and non-typhoidal) is a serious infection that poses problems for treatment due to its MDR nature 
Table 4. Antimicrobial resistance and Plasmid profiles of Salmonella isolates from different sources.

\begin{tabular}{|c|c|c|c|c|c|}
\hline Salmonella isolates & Sources & Resistance pattern & Plasmid profile & Approx. plasmid size & No of plasmids isolated \\
\hline S. typhi 01 & Food & TET, AMP, COT, COL & A & $25,30.2$ & 2 \\
\hline S. typhi 03 & Faeces & TET, AMP, COT, COL & B & 30.2 & 1 \\
\hline S. enteritidis 01 & Food & TET, AMP, COT, COL & A & $25,30.2$ & 2 \\
\hline S. enteritidis 04 & Well-water & TET, AMP, COT, COL & $\mathrm{C}$ & $7.2,21.5$ & 2 \\
\hline S. enteritidis 03 & Faeces & TET, AMP, COT, COL & B & 30.2 & 1 \\
\hline S. typhimurium 04 & Food & TET, AMP, COT, COL & $\mathrm{D}$ & 25 & 1 \\
\hline S. enteritidis 05 & Faeces & TET, AMP, COT, COL & $\mathrm{E}$ & 5.0 & 1 \\
\hline S. typhimurium 05 & Food & TET, AMP, COT, COL & A & $25,30.2$ & 2 \\
\hline S. typhimurium 06 & Food & TET, AMP, COT, COL & $\mathrm{F}$ & 0 & 0 \\
\hline S. typhimurium 01 & Well-water & TET, AMP, COT, COL & $\mathrm{F}$ & 0 & 0 \\
\hline S. typhimurium 02 & Well-water & TET, AMP, COT, COL & $\mathrm{F}$ & 0 & 0 \\
\hline S. typhimurium 09 & Faeces & TET, AMP, COT, COL & G & $21.5,25$ & 2 \\
\hline S. typhimurium 07 & Hand-swab & TET, AMP, COT, COL & A & $25,30.2$ & 2 \\
\hline S. choleraesuis 03 & Faeces & TET, AMP, COT, COL & B & 30.2 & 1 \\
\hline S. choleraesuis 05 & Faeces & TET, AMP, COT, COL & B & 30.2 & 1 \\
\hline S. choleraesuis 02 & Blood & TET, AMP, COT, COL & $\mathrm{H}$ & 7.5 & 1 \\
\hline S. arizonae & Faeces & TET, AMP, COT, COL & I & 15.0 & 1 \\
\hline S. typhi 05 & Food & TET, AMP, COL, CIP & $\mathrm{F}$ & 0 & 0 \\
\hline S. enteritidis 02 & Faeces & TET, AMP, COL, CIP & $\mathrm{J}$ & $17.5,30.2$ & 2 \\
\hline S. typhi 02 & Faeces & TET, AMP, COL, COT, CIP & $\mathrm{J}$ & $17.5,30.2$ & 2 \\
\hline S. typhi 04 & Faeces & TET, AMP, COL, COT, CIP & K & $21.2,25,30.2$ & 3 \\
\hline S. enteritidis 06 & Water-sachet & TET, AMP, COL & $\mathrm{L}$ & $3.2,7.2$ & 2 \\
\hline S. typhimurium 03 & Water-sachet & TET, AMP, COL & M & $5.0,7.2$ & 2 \\
\hline S. typhimurium 08 & Hand-swab & TET, AMP, COL & G & $21.5,25$ & 2 \\
\hline S. choleraesuis 01 & Blood & TET, AMP, COL & $\mathrm{L}$ & $3.2,7.2$ & 2 \\
\hline S. choleraesuis 04 & Faeces & TET, AMP, COL & B & 30.2 & 1 \\
\hline S. virchow & Faeces & TET, AMP, COL & A & $25,30.2$ & 2 \\
\hline
\end{tabular}
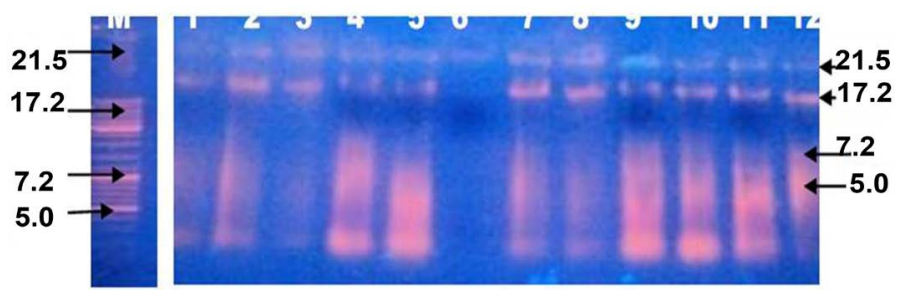

Figure 1. Plasmid profile gel analysis of Salmonella isolates; M: Hind III digested 1 DNA (DNA Maker (Inqaba Biotech, South Africa) $+10 \mathrm{~kb}$ DNA markers; Lane 1: Salmonella typhi-01 (food); Lane 2: Salmonella enteritidis-01 (food); Lane 3: Salmonella enteritidis-02 (faeces); Lane 4: Salmonella enteritidis-03 (faeces); Lane 5: Salmonella enteritidis-04 (food); Lane 6: Salmonella enteritidis-05 (well-water): Lane 7: Salmonella typhi-01(food): Lane 8: Salmonella enteritidis-06 (water-sachet); Lane 9: Salmonella typhi-02(faeces); Lane 10: Salmonella typhi-03 (faeces): Lane 11: Salmonella typhi-04 (faeces); Lane 12: Salmonella enteritidis-01 (food); Lane 13: Salmonella enteritidis-02 (faeces). 


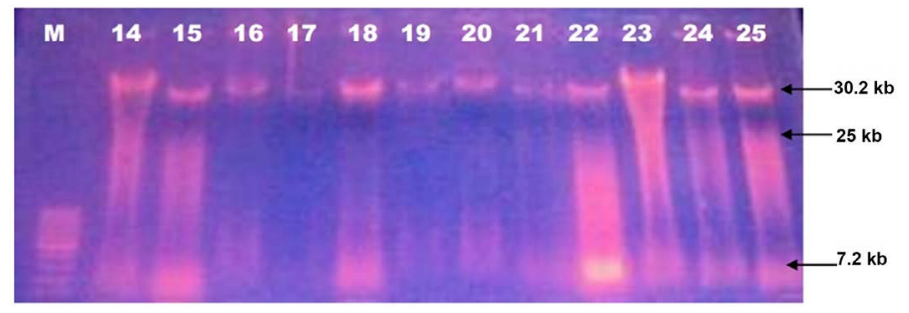

Figure 2. Plasmid profile gel analysis of Salmonella isolates; M: Hind III digested 1 DNA (DNA Maker (Inqaba Biotech, South Africa) + $10 \mathrm{~kb}$ DNA markers; Lane 14: Salmonella typhi-04 (faeces); Lane 15: Salmonella typhimurium-03 (water-sachet); Lane 16: Salmonella typhimurium-04 (food); Lane 17: Salmonella typhimurium-05 (food); Lane 18: Salmonella typhimurium-05 (food); Lane 19: Salmonella typhimurium-07 (hand swab); Lane 20: Salmonella typhimurium-08 (hand swab); Lane 21: Salmonella typhimurium-09 (faeces); Lane 22: Salmonella arizonae (faeces); Lane 23: Salmonella choleriusuis (blood); Lane 24: Salmonella choleriusuis (blood); Lane 25: Salmonella choleriusuis (faeces).

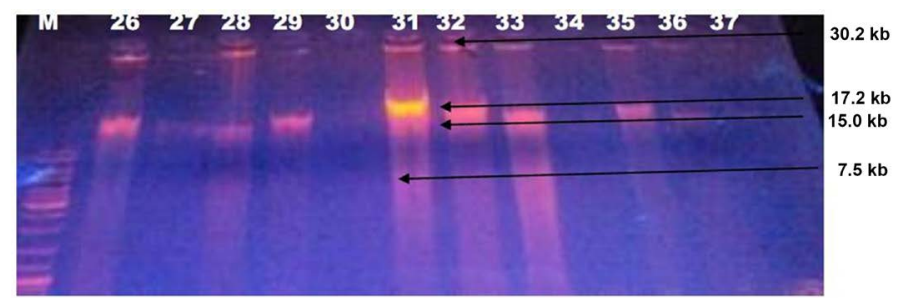

Figure 3. Plasmid profile gel analysis of Salmonella isolates; M: Hind III digested 1 DNA (DNA Maker (Inqaba Biotech, South Africa) + 10 kb DNA markers; Lane 26: Salmonella choleriusuis (faeces); Lane 27: Salmonella choleriusuis (faeces); Lane 28: Salmonella virchow (faeces); Lane 29: Salmonella virchow (faeces); Lane 30: Salmonella enteritidis-05 (well water); Lane 31: Salmonella typhimurium-07 (hand swab); Lane 32: Salmonella typhimurium-08 (hand swab); Lane 33: Salmonella choleriusuis (blood); Lane 34: Salmonella typhimurium-09 (faeces); Lane 35: Salmonella typhimurium-03 (water-sachet); Lane 36: Salmonella enteritidis-06 (water-sachet); Lane 37: Salmonella typhi-04 (faeces).

in many parts of the world. Drug resistance is a global crisis affecting human health, livestock, and the economy [36] with significant adverse impact on clinical outcomes and high cost of treatment [7].

In this study, twenty-seven (27) Salmonella strains which included 11 (15.1\%) from faecal sample, 7 (9.6\%) food, 3 (4.1\%) well-water and 2 (2.7\%) each from blood, sachet-water and hand-swab samples were identified. The isolation of Salmonella strains from faecal and food samples indicates that the pathogen is prevalent and endemic in our locality. Food and water remain the major vehicles of transmission of Salmonellosis [37]. Similar observations were recorded in Ado-Ekiti, Southwest Nigeria [37]. Owoseni and Onilude [38] also isolated different enteric bacteria pathogens including Salmonella enterica from food samples in four different West African countries (Nigeria, Togo, Ghana and Benin Republic). In this study, nine (33.3\%) S. typhimurium, the most prevalence se- 
rotype was isolated from all the sources evaluated. Salmonella typhimurium had been documented to be the leading cause of non-typhoidal salmonellosis globally [39]. Other Salmonella serovars recorded in this study are $S$. enteritidis, $S$. choleraesuis, $S$. arizonae etc. The implication of this is the continual horizontal spread of non-typhoidal salmonellosis within Lagos metropolis. The present study shared similarity with the previous report by Akinyemi et al. [40] where different bacteria genera including Salmonella particularly S. typhimurium were isolated from vended foods in Lagos. Also, similar observation of contaminated well-water and vended foods were recorded by Umaru et al., [41] in Taraba State Northwest Nigeria. The detection of these strains or other enteric bacterial pathogens most especially in water and food is an indication of poor quality control being maintained by some sachet-water producing companies and food vendors as well as handlers of these products thus posing a potential threat to public health. Therefore, an urgent attention from National Agency for Food and Drugs Administrations and Control (NAFDAC) is needed for quality standardizations check.

Nevertheless, it should be noted that Salmonella choleraesuis was isolated from the blood samples of patient diagnosed of typhoid fever. Isolation of invasive non-typhoidal Salmonella had been reported in Kenya [42] [43]

High antibiotic resistance rate was found in all the twenty-seven (27) Salmonella strains isolated across different sources in this study as most were resistant to 3 or more antibiotics. All the 27 Salmonella isolates were resistant to tetracycline ampicillin and colistin and $66.67 \%$ of the isolates were resistant to cotrimoxazole. This result was consistent with the study conducted in Abakaliki, Nigeria and that of the study conducted in Ibadan, Southwest, Nigeria where majority of the Salmonella isolated from faeces, sachet-water and bore-hole water were MDR; chloramphenicol, tetracyclin, ampicillins, sulfomothazole and trimethoprim [44] [45]. It is pertinent to note that four (4) distinct resistance profiles: A (TetAmpCol), B (TetAmpColCot), C (TetAmpColCip) and D (TetAmpColCotCip), with resistant profile B being the most frequently encountered profile occurring in 17 (62.9\%) Salmonella isolates. Resistance profiles C and D contained ciprofloxacin resistance phenotypic trait of Salmonella isolates particularly $S$. typhi and $S$. enteritidis. It was observed that four Salmonella strains were involved in the resistance pattern with $S$. typhi and $S$. enteritidis possessing resistance pattern C, while, two $S$. typhi strains isolated from faecal samples possessed resistance pattern D (TetAmpColCotCip). However, some Salmonella species have more than one resistance profile, for instance $S$. enteritidis isolated from different sources had 3 resistance profiles A, B and C (Table 4) thus, limiting the discriminating capacity of antibiotic resistance profile as a typing tool for epidemiological purpose. Ammari et al. [46] observed that 9 out of the 16 Salmonella isolates identified exhibited the same resistance patterns.

Twenty-three (85.2\%) out of the 27 Salmonella isolates harboured one or more plasmid DNA ranging in size from $3.2 \mathrm{~kb}-30.2 \mathrm{~kb}$ exhibiting 12 plasmid 
profiles.. For instance, profiles A, C, G, J, K, L and M were made up of plasmid sizes $(25,30.2) \mathrm{kb},(7.2,21.5) \mathrm{kb},(21.5,25) \mathrm{kb},(17.5,30.2) \mathrm{kb},(21.2,25,30.2) \mathrm{kb}$, $(3.2,7.2) \mathrm{kb}$ and $(5.0,7.2) \mathrm{kb}$ respectively. However, some profiles were made up of single plasmid size, these include, profiles B, D, E, H and I with $30.2 \mathrm{~kb}, 25 \mathrm{~kb}$, $5.0 \mathrm{~kb}, 7.5 \mathrm{~kb}$ and $15.0 \mathrm{~kb}$ respectively. The largest profile clustered was profile $\mathrm{B}$ made up of 6 (22\%) Salmonella isolates with two plasmids size of $25 \mathrm{~kb}$ and 30 $\mathrm{kb}$. It is interesting to note that, 17 different Salmonella isolates showed the same resistance profile TetAmpCol with 9 different plasmid profiles ranging from 3.2 $\mathrm{kb}$ to $30.2 \mathrm{~kb}$ in size. For instance, $S$. typhimurium 04 and 05 isolated from food were found to possess the same resistance profile of B (TetAmpColCot), but different plasmid DNA sizes of $5.0 \mathrm{~kb}$ and $30.2 \mathrm{~kb}$ respectively. Similarly, S. typhi 02 and 04 isolated from faecal samples with the same resistance profile of A (TetAmpCol), possessed different plasmid profiles of $17.5 \mathrm{~kb}$ and $30.2 \mathrm{~kb}$ for $S$. typhi 02 and $21.5 \mathrm{~kb}, 25 \mathrm{~kb}$ and $30.2 \mathrm{~kb}$ for $S$. typhi 04 . This means that, organisms of the same species isolated from different sources may differ in plasmid profile. Furthermore, S. choleraesuis 01 (blood) and S. choleraesuis 04 (faeces) possessed the same resistance profile A (TetAmpCol) but differed in plasmid profile in that $S$. choleraesuis 01 from blood sample harboured 2 plasmids of 3.2 $\mathrm{kb}$ and $7.2 \mathrm{~kb}$ in sizes while $S$. choleraesuis 04 (faeces) possessed only one plasmid of $30.2 \mathrm{~kb}$. This result indicated that, plasmid profile has a good discriminating tool of characterizing Salmonella isolates compared to antibiotic resistance profiles for epidemiological purpose. This finding was in agreement with several reports published elsewhere [47] [48] [49] [50] on the better discriminatory ability of plasmid profile than antimicrobial resistance profile. Nevertheless, plasmid profiling has its limitation as it could be lost or gain and could also be inserted into transposon and chromosomes of pathogenic organisms [16] [50], which also limits its capability as a good tool for tracking the actual cause of disease outbreak.

Generally, this study revealed that all the Salmonella isolates were MDR and most of which harboured plasmid DNA of different sizes ranging from $3.2 \mathrm{~kb}$ $30.2 \mathrm{~kb}$. This study did not ascertain whether or not plasmids were responsible for resistant in Salmonella isolates, as plasmid curing was not performed a limitation that is worthwhile. Plasmid profile exhibited high discriminatory capability compared with antimicrobial resistance profile with low discriminatory capability. It provides important information regarding the dissemination of antimicrobial resistance properties and emphasized the need to exploring molecular typing methods in Salmonella epidemiology and surveillance, and to determine whether the resistance possessed by these organisms are plasmid mediated. Further studies on gene sequencing and expression are essential for better infection control.

\section{Acknowledgements}

The assistance and supports of the entire staff of Microbiology department, La- 
gos State University and Biochemistry department, Nigeria Institute of Medical Research, Yaba, Lagos Nigeria are greatly appreciated. We are also grateful to all the staff of the hospitals used.

\section{References}

[1] Salehi, T.Z., Mahzounieh, M. and Saeedzadeh, A. (2005) Detection of InvA Gene in Isolated Salmonella from Broilers by PCR Method. International Journal of Poultry Science, 4, 557-559. https://doi.org/10.3923/ijps.2005.557.559

[2] Popoff, M.Y., Parry, C.M. and Le Minor, L. (1997) Antigenic Formula of the Salmonella Serovars. 7th Revision, World Health Organisation, A Consorting Centre for Reference and Research on Salmonella, Pasteur Institute, Paris, 56-87.

[3] Grimont, P.A.D. and Weill, F.X. (2007) Antigenic Formulae of the Salmonella serovars. 9th Edition, WHO Collaborating Center for Reference and Research on Salmonella at Institute Pasteur in France, Paris, 150 p.

[4] CDC (2010) Salmonella. http://www.cdc.gov/Salmonella/

[5] Swartz, M.N. (2002) Human Diseases Caused by Food-Borne Pathogens of Animal Origin. Clinical Infectious Diseases, 34, 111-122. https://doi.org/10.1086/340248

[6] Lazaro, N.A., Tibana, D.P., Rodrigues, E., Reis, B.Q. and Hofer, E. (2004) Antimicrobial Resistance and R-Plasmids in Salmonella spp. from Swine and Abattoir Environment. Pesquisa Veterinária Brasileira, 24, 57-60. https://doi.org/10.1590/S0100-736X2004000200001

[7] Health Organisation (WHO) (2014a) Antimicrobial Resistance Global Report on Surveillance. X1-28.

[8] Crump, J.A., Luby, S.P. and Minz, E.D. (2003) The Global Burden of typhoid Fever. Bulletin of the World Health Organization, 82, 346-353.

[9] Crump, J.A. and Mintz, E.D. (2010) Global Trends in Typhoid and Paratyphoid Fever. Clinical Infectious Diseases, 50, 241-246. https://doi.org/10.1086/649541

[10] Morpeth, S.C., Ramadhani, H.O. and Crump, J.A. (2009) Invasive Non-Typhi Salmonella Disease in Africa. Clinical Infectious Diseases, 49, 606-611. https://doi.org/10.1086/603553

[11] Reddy, E.A., Shaw, A.V. and Crump, J.A. (2010) Community-Acquired Bloodstream Infections in Africa: A Systematic Review and Meta-Analysis. The Lancet Infectious Diseases, 10, 417-432. https://doi.org/10.1016/S1473-3099(10)70072-4

[12] Basnyat, B., Maskey, A.P., Zimmerman, M.D. and Murdoch, D.R. (2005) Enteric (Typhoid) Fever in Travelers. Clinical Infectious Diseases, 41, 1467-1472. https://doi.org/10.1086/497136

[13] Chau, T.T., Campbell, J.I., Galindo, C.M., Hoang, N.V., et al. (2007) Antimicrobial Drug Resistance of Salmonella enterica Serovar Typhi in Asia and Molecular Mechanisms of Reduced Susceptibility to the Fluoroquinolones. Antimicrobial Agents and Chemotherapy, 51, 4315-4323. https://doi.org/10.1128/AAC.00294-07

[14] Parry, C.M. and Threlfall, E.J. (2008) Antimicrobial Resistance in Typhoidal and Nontyphoidal Salmonellae. Current Opinion in Infectious Diseases, 21, 531-538.

[15] Su, L.H., Chiu, C.H., Chu, C. and Ou, J.T. (2004) Antimicrobial Resistance in Nontyphoid Salmonella Serotypes: A Global Challenge. Clinical Infectious Diseases, 39, 546-551. https://doi.org/10.1086/422726

[16] Adeshina, G.O., Osuagwu, N., Okeke, C.E. and Ehinmidu, J.O. (2010) Plasmid DNA Analysis and Conjugative Study of Antibiotics Resistant Salmonella typhi and para- 
typhi to Ten Selected Antibiotics in Zaria, Nigeria. African Journal of Pharmacy and Pharmacology, 4, 151-157.

[17] El-Sayed, M.A., Tawakol, W.M., Ragab, Y.M. and Amin, M.A. (2012) Phenotypic Detection of Potential Antimicrobial Resistance among Environmental Salmonella Species. International Journal of Microbiology Research, 3, 38-45.

[18] Akinyemi, K.O., Iwalokun, B.A., Alafe, O.O., Mudashiru, S.A. and Fakorede, C.

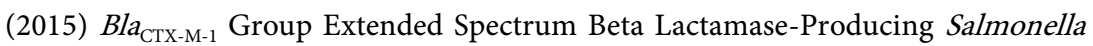
typhi from Hospitalized Patients in Lagos, Nigeria. Infection and Drug Resistance, 2015, 99-106. https://doi.org/10.2147/IDR.S78876

[19] Miriagou, V., Carattoli, A. and Fanning, S. (2006) Antimicrobial Resistance Islands: Resistance Gene Clusters in Salmonella Chromosome and Plasmids. Microbes and Infection, 8, 1923-1930. https://doi.org/10.1016/j.micinf.2005.12.027

[20] Murray, B.E. (1986) Resistance of Shigella, Salmonella and Other Selected Enteric Pathogens to Antimicrobial Agents. Reviews of Infectious Diseases, 8, 172-181.

[21] Health Organisation (WHO) (2014) Briefing Note-Antimicrobial Resistance: An Emerging Water Sanitation and Hygiene Issue. WHO/FWC/WSH/14.7.

[22] Van, T.T.H., Moutafis, G., Istivan, T., Tran, L.T. and Coloe, P.J. (2007) Detection of Salmonella spp. in Retail Raw Food Samples from Vietnam and Characterization of Their Antibiotic Resistance. Applied and Environmental Microbiology, 73, 6885-6890. https://doi.org/10.1128/AEM.00972-07

[23] Sun, M. (1984) In Search of Salmonella's Smoking Gun. Science, 226, 30-32. https://doi.org/10.1126/science.6566452

[24] Glynn, M.K., Boppy, C., Dewitt, W., Dabney, P., Mokhtar, M. and Angulo, F.J. (1998) Emergence of Multi-Drug Resistant Salmonella enterica Serovar Typhimurium DT104 Infections in the United States. New England Journal of Medicine, 338, 1333-1338. https://doi.org/10.1056/NEJM199805073381901

[25] Carattoli, A., Filetici, E., Villa, L., Dionisi, A.M., Ricci, A. and Luzzi, I. (2002) Antibiotic Resistance Genes and Salmonella Genomic Island 1 in Salmonella enterica Serovar Typhimurium Isolated in Italy. Antimicrobial Agents and Chemotherapy, 46, 2821-2828. https://doi.org/10.1128/AAC.46.9.2821-2828.2002

[26] Helms, M., Vastrup, P., Gerner-Smidt, P. and Molbak, K. (2003) Short and Long Term Mortality Associated with Foodborne Bacterial Gastrointestinal Infections: Registry Based Study. BMJ, 326, 357.

[27] Tanxe, R. (1999) Salmonella Enteritis and Salmonella Typhimurium DT104: Successful Subtypes in the Modern World. In: Scheld, W.M., Craig, W.A. and Hughes, J.M., Eds., Emerging Infections, ASM Press, Washington, 37-52.

[28] Davis, J. (1994) Inactivation of Antibiotics and Dissemination of Resistance Genes. Science, 264, 375-382. https://doi.org/10.1126/science.8153624

[29] Chu, C.H., Su, L.H. and Chiu, C. (2004) Salmonella enterica Serotype Choleraesuis. Epidemiology, Pathogenesis, Clinical Disease and Treatment. Clinical Microbiology Reviews, 17, 311-322. https://doi.org/10.1128/CMR.17.2.311-322.2004

[30] Ben, S.I., Mzoughi, R. and Aouni, M. (2008) Laboratory Typing Methods for Diagnostic of Salmonella Strains, the "Old" Organism That Continued Challenges. Annals of Microbiology, 60, 1-25.

[31] Mackie, T.J. and McCartney, J.E. (1989) Practical Medical Microbiology. In: College, J.C., Dugluid, J.P., Frasor, A.G. and Marmion, B.P., Eds., WHO Guideline for Drinking Water Quality, 13th Edition, Vol. 12, Churchill Livingstone, London, 910.

[32] Tambekar, D.H., Shirsat, S.D., Suradkar, S.B., Rajankar, P.N. and Banginwar, Y.S. 
(2007) Prevention of Transmission of Infectious Disease: Studies on Hand Hygiene in Health-Care among Students. Continental Journal of Biomedical Sciences, 1, 6-10.

[33] Clinical and Laboratory Standards Institute (CLSI) (2008) Performance Standards for Antimicrobial Disk and Dilution Susceptibility Tests for Bacteria Isolated from Animals; Approved Standard-Third Edition. Document M31-A3, Clinical and Laboratory Standards Institute, Wayne, Pennsylvania, 19087-1898.

[34] Liu, S.T. (1981) Rapid Procedure for Detection and Isolation of Large and Small Plasmids. Journal of Bacteriology, 145, 1365-1373.

[35] Meyers, J.A., Sanchez, D., Elwell, L.P. and Falkow, S. (1976) Simple Agarose Gel electrophoretic Method for the Identification and Characterization of Plasmid Deoxyribonucleic Acid. Journal of Bacteriology, 127, 1529-1537.

[36] Anon (2015) Nice Antimicrobial Stewardship: Right Drug, Dose, and Time? Editorial. The Lancet, 386, 717. https://doi.org/10.1016/S0140-6736(15)61522-7

[37] David, O.M., Adelapo, D.A., Moro, D.D., Esan, C.O, Oje, O.J. and Famurewa, O. (2015) Prevalence and Carriage Status of Salmonella typhi among Students of Ekiti State University, Ado-Ekiti, Nigeria. International Journal of Biosciences, 6, 1-8. https://doi.org/10.12692/ijb/6.10.1-8

[38] Owoseni, A. and Onilude, A. (2016) Incidence and Plasmid Profiles of Multidrug Resistant Enterobacteria Isolates from Processed Convenience Foods in Some Countries of West Africa. Food and Public Health, 6, 44-51.

[39] Majowicz, S.E., Musto, J. and Scallan, E. (2010) The International Collaboration on Enteric Disease "Burden of Illness" Studies: The Global Burden of Nontyphoidal Salmonella Gastroenteritis. Clinical Infectious Diseases, 50, 882-889. https://doi.org/10.1086/650733

[40] Akinyemi, K.O., Fashola, M.O., Habib, N. and Akinwande, E. (2013) Vended Foods in Lagos, Nigeria: A Potential Reservoir for the Spread of Emerging Strains of Drug Resistant Bacteria. Health, 5, 675-680. https://doi.org/10.4236/health.2013.54089

[41] Umaru, G.A., Adamu, Z., Ishaya, D., Abubakar, Y.U., Hussaini, A., Umar, M., Adamu, S.G. and Adamu, N.B. (2015) Prevalence and Antimicrobial Resistance Pattern of Escherichia coli in Drinking Waters in Jalingo Metropolis, Taraba State, North-Eastern Nigeria. Microbiology Research International, 3, 8-13.

[42] Kariuki, S., Revathi, G., Kariuki, N., et al. (2006) Invasive Multidrug-Resistant Non-Typhoidal Salmonella Infections in Africa: Zoonotic or Anthroponotic Transmission? Journal of Medical Microbiology, 55, 585-591. https://doi.org/10.1099/jmm.0.46375-0

[43] Akinyemi, K.O., Oyefolu, A.O., Omonigbehin, E.O., Akinside, K.A. and Coker, A.O. (2000) Evaluation of Blood Collected from Clinically Diagnosed Typhoid Fever Patients in the Metropolis of Lagos, Nigeria. Journal of Nigerian Infection Control Association, 3, 25-30. https://doi.org/10.4314/jnica.v3i2.10722

[44] Okeke, O.C., Iroha, I.R., Nwadiogbu, I.A., Agumah, N., Eni, O. and Odinkemere, S.C. (2015) Antimicrobial Resistance Pattern of Coliform Bacteria Isolated from Sachet and Borehole Waters Sold in Abakaliki Metropolis of Ebonyi State, Nigeria. International Journal of Innovation and Scientific Research, 16, 526-532.

[45] Fashae, K., Ogusola, F., Aerestrup, F.M. and Hendriksen, R.S. (2010) Antimicrobial Susceptibility and Serovars of Salmonella from Chicken and Human in Ibadan, Nigeria. The Journal of Infection in Developing Countries, 4, 484-494.

[46] Ammari, S., Laglaoui, A., En-Nanei, L., Bertrand, S., Wildemauwe, C., Said, B. and Mohammed, A. (2009) Isolation, Drug Resistance and Molecular Characterization of Salmonella Isolates in Northern Morocco. The Journal of Infection in Developing 
Countries, 3, 41-49.

[47] Ling, J.M., Chan, E.W.C. and Cheng, A.F. (2001) Molecular Epidemiological Analysis of Salmonella enterica Serotype Derby Infections in Hong Kong. Journal of Infection, 42, 145-153. https://doi.org/10.1053/jinf.2001.0806

[48] Wain, J. and Kidgell, C. (2004) The Emergence of Multidrug Resistance to Antimicrobial Agents for the Treatment of Typhoid Fever. Transactions of the Royal Society of Tropical Medicine and Hygiene, 98, 423-430.

https://doi.org/10.1016/j.trstmh.2003.10.015

[49] Rychlik, I., Gregorova, D. and Hradecka, H. (2006) Distribution and Function of Plasmids in Salmonella enterica. Veterinary Microbiology, 112, 1-10.

https://doi.org/10.1016/j.vetmic.2005.10.030

[50] Learn-Han, L., Yoke-Kqueen, C., Shiran, M.S., Sabrina, S., Noor-Zaleha, A.S., Sim, J.H., Chai-Hoon, K. and Son, R. (2009) Molecular Characterization and Antimicrobial Resistance Profiling of Salmonella enterica Subsp. enterica Isolated from "Selom" (Oenanthe stolonifera). International Food Research Journal, 16, 191-202. 